\title{
Translation and Validation of the Korean Version of the 39-Item Parkinson's Disease Questionnaire
}

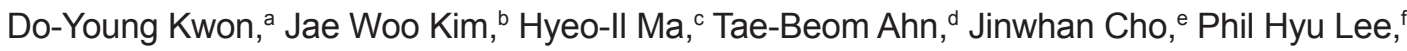 \\ Sun Ju Chung, ${ }^{9}$ Joong-Seok Kim, ${ }^{\text {h }}$ Jong Sam Baik, ${ }^{i}$ Seong-Beom Koh ${ }^{\mathrm{a}}$ \\ aDepartment of Neurology, Korea University College of Medicine, Seoul, Korea \\ bDepartment of Neurology, Dong-A University College of Medicine, Busan, Korea \\ 'Department of Neurology, Hallym University College of Medicine, Anyang, Korea \\ dDepartment of Neurology, Kyung Hee University College of Medicine, Seoul, Korea \\ eDepartment of Neurology, Samsung Medical Center, Sungkyunkwan University School of Medicine, Seoul, Korea \\ 'Department of Neurology, Severance Hospital, Yonsei University College of Medicine, Seoul, Korea \\ gParkinson/Alzheimer Center, Department of Neurology, Asan Medical Center, University of Ulsan College of Medicine, Seoul, Korea \\ ${ }^{h}$ Department of Neurology, The Catholic University of Korea College of Medicine, Seoul, Korea \\ 'Department of Neurology, Sanggye Paik Hospital, Inje University College of Medicine, Seoul, Korea
}

Received February 21, 2012

Revised June 8, 2012

Accepted June 8, 2012

\section{Correspondence}

Seong-Beom Koh, MD, PhD

Department of Neurology,

Korea University College

of Medicine, Guro Hospital,

148 Gurodong-ro, Guro-gu,

Seoul 152-703, Korea

Tel $+82-2-2626-3169$

Fax $+82-2-2626-3169$

E-mail parkinson@korea.ac.kr
Background and Purpose The importance of health-related quality of life (HrQoL) has been increasingly emphasized when assessing and providing treatment to patients with chronic, progressive, degenerative disorders. The 39-item Parkinson's disease questionnaire (PDQ-39) is the most widely used patient-reporting scale to assess HrQoL in Parkinson's disease (PD). This study evaluated the validity and reliability of the translated Korean version of the PDQ-39 (K-PDQ-39).

Methods One hundred and two participants with PD from 10 movement disorder clinics at university-affiliated hospitals in South Korea completed the K-PDQ-39. All of the participants were also tested using the Unified Parkinson's Disease Rating Scale (UPDRS), Korean version of the Mini-Mental State Examination (K-MMSE), Korean version of the Montgomery-Asberg Depression Scale (K-MADS), Epworth Sleepiness Scale (ESS) and non-motor symptoms scale (NMSS). Retests of the K-PDQ-39 were performed over time intervals from 10 to 14 days in order to assess test-retest reliability.

Results Each K-PDQ-39 domain showed correlations with the summary index scores $(\mathrm{rS}=0.559-0.793, p<0.001)$. Six out of eight domains met the acceptable standard of reliability (Cronbach's $\alpha$ coefficient $\geq 0.70$ ). The Guttman split-half coefficient value of the K-PDQ-39 summary index, which is an indicator of test-retest reliability, was $0.919(p<0.001)$. All of the clinical variables examined except for age, comprising disease duration, levodopa equivalent dose, modified Hoehn and Yahr stage (H\&Y stage), UPDRS part I, II and III, mood status (KMADS), cognition (K-MMSE), daytime sleepiness (ESS) and (NMSS) showed strong correlations with the K-PDQ-39 summary index $(p<0.01)$.

Conclusions The K-PDQ-39 has been validated for use in the Korean-speaking PD population. The questionnaire is a valid and reliable assessment tool for assessing the HrQoL of Korean PD patients.

J Clin Neurol 2013;9:26-31

Key Words Parkinson's disease, quality of life, validation.

@ This is an Open Access article distributed under the terms of the Creative Commons Attribution Non-Commercial License (http://creativecommons.org/ licenses/by-nc/3.0) which permits unrestricted non-commercial use, distribution, and reproduction in any medium, provided the original work is properly cited. 


\section{Introduction}

Parkinson's disease (PD), which is both chronic and progressive, is the second most common neurodegenerative disorder, and its prevalence is increasing rapidly. ${ }^{1,2}$ Health-related quality of life (HrQoL) is considered critical in chronically ill patients, especially in the elderly, and PD research is increasingly focused on factors affecting the HrQoL. ${ }^{3}$ Although motor features have until recently dominated clinical impact assessments in patients with PD, non-motor symptoms are currently attracting more attention as determinants of HrQoL in PD, ${ }^{4,5}$ with a growing emphasis on the importance of $\mathrm{HrQoL}$ issues when initiating and maintaining treatment.,

The 39-item Parkinson's disease questionnaire (PDQ-39), which contains 39 items involving 8 discrete dimensions that mainly evaluate $\mathrm{HrQoL}$, is the representative disease-specific tool for assessing HrQoL in PD. The PDQ-39 evaluates mobility, activities of daily living, emotional well-being, stigma, social support, cognition, communication, bodily discomfort and summary index. ${ }^{7,8}$ The PDQ-39 was originally developed in Britain and has been translated into and validated in many different languages worldwide. ${ }^{9-13}$ Because perceptions of $\mathrm{HrQoL}$ are subjective and may vary according to cultural and individual backgrounds, translated and validated versions tailored for different cultural contexts are required for research.

The aim of the present study was to translate the PDQ-39 into Korean and to validate the reliability and consistency of the new Korean version as well as its feasibility for use in future assessments of HrQoL in the Korean-speaking PD population.

\section{Methods}

\section{Subjects}

One hundred and two PD patients from 10 movement-disorder centers at university-affiliated hospitals in South Korea who met the clinical diagnostic criteria of the United Kingdom Parkinson's Disease Society Brain Bank ${ }^{14}$ were enrolled in the present study. The obligatory inclusion criterion for all participants was no change in anti-parkinsonian drugs for at least the previous 4 weeks. The exclusion criteria included patients who were younger than 40 years at the onset of $\mathrm{PD}$, had possible secondary causes of PD such as drugs or structural brain lesions that can induce parkinsonism, who were taking medications including antidepressants that could affect cognitive function, or had impaired cognitive function represented by a total Mini-Mental State Examination score of less than 24. All subjects provided written informed consent for unprompted study participation. Ethical approval was obtained from the joint ethics committee of each participating university hospital.

\section{Translation}

The original PDQ-39 was translated into Korean using forward and backward translation, expert committee review and pretests of the translated Korean version of the PDQ-39 (K-PDQ39). Two independent bilingual translators translated the original British version of the PDQ-39 into Korean. The translated Korean version was then translated back into British English by another bilingual translator who had no knowledge of the original version of the questionnaire. The back-translated version was then compared to the original version by the same translators. An expert committee (comprising D.Y. Kwon, J.S. Baik and S.B. Koh) reviewed the translated version and modified the draft version until a consensus was reached among them. After pretesting the translated version in four patients, the K-PDQ-39 was finalized and used in subsequent analyses.

\section{K-PDQ-39}

The K-PDQ-39 comprises 39 items involving 8 discrete dimensions: mobility, activities of daily living, emotional wellbeing, stigma, social support, cognition, communication and bodily discomfort. The assessment period is the "previous 1 month." Each item is scored on a 5-point Likert scale ranging from 0 ("never") to 4 ("always"). The total K-PDQ-39 score is expressed as a percentage ranging from 0 to 100 .

\section{Data collection}

All of the authors, who were experts in movement disorders and experienced interviewers from each movement center, conducted the following assessments of subjects in order to assess and qualify non-motor symptoms in PD patients and K-PDQ39: basic demographics, levodopa equivalent dose (LDED), ${ }^{15}$ modified Hoehn and Yahr (H\&Y) stage, ${ }^{16}$ Unified Parkinson's Disease Rating Scale (UPDRS) parts I, II, and III, ${ }^{17}$ the Korean version of the Mini-Mental State Examination (K-MMSE) ${ }^{18}$ for measuring cognitive function, the Korean version of the Montgomery-Asberg Depression Scale (K-MADS), the Epworth Sleepiness Scale (ESS), ${ }^{19}$ and the non-motor symptoms scale (NMSS) ${ }^{20}$ Participants returned to outpatient clinics for retests using the K-PDQ-39 in order to assess test-retest reliability over time intervals of from 10 to 14 days, which was a sufficient delay to minimize memory or practice effects.

\section{Statistical analysis}

Reliability was assessed in order to measure the internal consistency and stability. Floor and ceiling effects involving less than $20 \%$ of the total population per domain were considered acceptable. ${ }^{35}$ Cronbach's $\alpha$ coefficient was calculated to analyze the internal consistency. The criterion value for $\alpha$ was $\geq 0.70$. Test-retest reliability was assessed using the Guttman Split-Half Coefficient analyses with values higher than 0.70 
considered indicative of acceptable reliability. The relationships between subscales of the K-PDQ-39 and other variables were analyzed using Spearman's rank correlation coefficients, since scores were not evenly distributed. These coefficients were also used to quantify the convergent validity with other clinical scales. SPSS (version 15.0 for Windows, Chicago, IL, USA) was used for all statistical analyses.

\section{Results}

\section{Demographic data}

A total of 102 patients (52 men and 50 women) were recruited for the study. The demographic data are listed in Table 1. Among the 102 PD patients, 75 (73.5\%) patients had H\&Y stages up to 2.0 (32 at stage 1, 12 at stage 1.5 , and 31 at stage 2 ) and $27(26.5 \%)$ had H\&Y stages of at least 2.5 (17 at stage 2.5, 9 at stage 3,1 at stage 4). Finally, 101 PD patients completed the K-PDQ-39 retest.

Table 1. Demographic data of PD patients

\begin{tabular}{lc}
\hline \multicolumn{1}{c}{ Subjecs ( $n=102)$} & Mean \pm SD \\
\hline Age (year) & $65.3 \pm 9.55$ \\
Sex (female : male) & $52: 50$ \\
Education (years) & $8.85 \pm 4.73$ \\
PD disease duration (months) & $43.64 \pm 48.17$ \\
LDED (mg) & $397.19 \pm 329.97$ \\
H\&Y stage & $1.82 \pm 0.70$ \\
UPDRS part I & $1.94 \pm 1.80$ \\
UPDRS part II & $5.97 \pm 5.90$ \\
UPDRS part III & $16.58 \pm 10.50$ \\
K-MMSE & $26.90 \pm 2.71$ \\
K-MADS & $10.37 \pm 10.09$
\end{tabular}

H\&Y stage: Hoehn and Yahr stage, K-MADS: Korean version Montgomery Asberg Depression Scale, K-MMSE: Korean version Mini-Mental Status Examination, LDED: levodopa equivalent dosage, PD: Parkinson's disease, SD: standard deviation, UPDRS: Unified Parkinson's Disease Rating Scale.

\section{Reliability and validity of the K-PDQ-39}

Table 2 lists the scores in each domain and the total score. The mean total summary index of the K-PDQ-39 was $23.20 \pm$ $18.63 \%$ (mean $\pm \mathrm{SD}$ ), and ranged from $0 \%$ to $74.9 \%$. A higher score in each K-PDQ-39 domain indicates greater discomfort felt by the patient: emotional well-being $(27.51 \pm 24.11 \%)$ and bodily discomfort $(26.43 \pm 23.38 \%)$ were the major complaints, while social support $(14.70 \pm 21.47 \%)$ and communication $(13.05 \pm 18.49 \%)$ were the least problematic. All of the KPDQ-39 domains showed acceptable ceiling effects. Emotional well-being and cognition domains were within the acceptable range of floor effects $(<20 \%)$, but the other six domains ranged from $21.6 \%$ to $52.9 \%$. Both the floor and ceiling effects of the SI were $0 \%$ (Table 2).

Each K-PDQ-39 domain showed significant correlations with summary index scores ( $\mathrm{rS}=0.559-0.793, p<0.001)$. Six of the eight domains met the standards of reliability (Cronbach's $\alpha$ coefficient $\geq 0.70$ ); the exceptions were stigma and social support (Table 3). For assessments of test-retest reliability, the Guttman Split-Half Coefficient value of the K-PDQ-39 summary index was $0.919(p<0.001)$. and ranged between 0.715 and 0.943 for the eight domains, which satisfied the standards

Table 3. Internal consistency (Cronbach's a coefficient) between subitem scores and the summary index score and test-retest reliability (Guttman Split-Half coefficient) of the K-PDQ-39 $(n=102)$

\begin{tabular}{lccc}
\hline $\begin{array}{c}\text { Subitems of the } \\
\text { K-PDQ-39 }\end{array}$ & Crohnbach's a & $\begin{array}{c}\text { Test-retest } \\
\text { reliability }\end{array}$ & p value \\
\hline Mobility & 0.78 & 0.943 & $<0.001$ \\
Activities of daily living & 0.80 & 0.932 & $<0.001$ \\
Emotional well-being & 0.73 & 0.870 & $<0.001$ \\
Stigma & 0.58 & 0.834 & $<0.001$ \\
Social support & 0.64 & 0.766 & $<0.001$ \\
Cognition & 0.77 & 0.835 & $<0.001$ \\
Communication & 0.75 & 0.874 & $<0.001$ \\
Bodily discomfort & 0.76 & 0.715 & $<0.001$ \\
PDQ-39 summary index & - & 0.919 & $<0.001$ \\
\hline K-PDQ: Korean version-Pakn
\end{tabular}

K-PDQ: Korean version-Parkinson's disease questionnaire.

Table 2. Scores in each item of K-PDQ-39 and correlations of items with total score of K-PDQ-39

\begin{tabular}{|c|c|c|c|c|c|c|}
\hline \multirow{2}{*}{ K-PDQ-39 sub-items } & \multicolumn{3}{|c|}{ Score ( $n=102)$ (Percentile) } & \multicolumn{2}{|c|}{ Spearman's rank correlation } & \multirow{2}{*}{ Floor/Ceiling effect (\%) } \\
\hline & Mean \pm SD & Min. & Max. & rS & $p$ value & \\
\hline Mobility & $22.25 \pm 26.50$ & 0 & 97.5 & 0.793 & $<0.001$ & $27.5 / 0$ \\
\hline Activities of daily living & $19.61 \pm 23.92$ & 0 & 87.5 & 0.758 & $<0.001$ & $30.4 / 0$ \\
\hline Emotional well-being & $27.51 \pm 24.11$ & 0 & 87.5 & 0.731 & $<0.001$ & $17.6 / 0$ \\
\hline Stigma & $18.18 \pm 19.65$ & 0 & 94.0 & 0.579 & $<0.001$ & $33.3 / 0$ \\
\hline Social support & $14.70 \pm 21.47$ & 0 & 91.7 & 0.559 & $<0.001$ & $51.9 / 0$ \\
\hline Cognition & $23.27 \pm 22.78$ & 0 & 91.7 & 0.772 & $<0.001$ & $17.9 / 0$ \\
\hline Communication & $13.05 \pm 18.49$ & 0 & 66.7 & 0.714 & $<0.001$ & $52.9 / 0$ \\
\hline Bodily discomfort & $26.43 \pm 23.38$ & 0 & 83.3 & 0.674 & $<0.001$ & $21.6 / 0$ \\
\hline PDQ-39 summary index & $23.30 \pm 18.63$ & 0 & 74.9 & & $<0.001$ & $0 / 0$ \\
\hline
\end{tabular}

K-PDQ: Korean version-Parkinson's disease questionnaire. 
Table 4. Spearman's correlation of the K-PDQ-39 and clinical features and rating scales

\begin{tabular}{lccccccccccc}
\hline \multicolumn{1}{c}{ K-PDQ-39 } & Age & $\begin{array}{c}\text { PD } \\
\text { duration }\end{array}$ & LDED & H\&Y stage & UPDRS1 & UPDRS2 & UPDRS3 & MADS & MMSE & ESS \\
\hline Mobility & $0.221^{\dagger}$ & $0.253^{*}$ & $0.297^{*}$ & $0.345^{*}$ & $0.562^{*}$ & $0.599^{*}$ & $0.362^{*}$ & $0.464^{*}$ & $-0.404^{*}$ & $0.311^{*}$ \\
Activities of daily living & 0.177 & $0.479^{*}$ & $0.400^{*}$ & $0.461^{*}$ & $0.455^{*}$ & $0.686^{*}$ & $0.384^{*}$ & $0.425^{*}$ & $-0.360^{*}$ & $0.300^{*}$ \\
Emotional well-being & 0.182 & 0.091 & 0.175 & 0.140 & $0.514^{*}$ & $0.427^{*}$ & 0.133 & $0.704^{*}$ & -0.028 & $0.244^{\dagger}$ \\
Stigma & 0.137 & $0.211^{\dagger}$ & $0.290^{*}$ & $0.188^{\dagger}$ & $0.462^{*}$ & $0.373^{*}$ & 0.094 & $0.444^{*}$ & 0.013 & $0.289^{*}$ \\
Social support & 0.076 & $0.240^{\dagger}$ & 0.083 & $0.198^{\dagger}$ & $0.291^{*}$ & $0.354^{*}$ & 0.152 & $0.459^{*}$ & -0.177 & $0.338^{*}$ \\
Cognition & 0.095 & $0.343^{*}$ & $0.361^{*}$ & $0.372^{*}$ & $0.539^{*}$ & $0.414^{*}$ & $0.309^{*}$ & $0.499^{*}$ & $-0.281^{*}$ & $0.391^{*}$ \\
Communication & 0.050 & $0.428^{*}$ & $0.394^{*}$ & $0.378^{*}$ & $0.449^{*}$ & $0.532^{*}$ & $0.335^{*}$ & $0.467^{*}$ & $-0.228^{\dagger}$ & $0.445^{*}$ \\
Bodily discomfort & 0.016 & $0.219^{\dagger}$ & $0.269^{*}$ & $0.204^{\dagger}$ & $0.290^{*}$ & $0.297^{*}$ & $0.210^{\dagger}$ & $0.442^{*}$ & $-0.242^{\dagger}$ & $0.263^{*}$ \\
PDQ-39 summary index & 0.097 & $0.359^{*}$ & $0.326^{*}$ & $0.356^{*}$ & $0.612^{*}$ & $0.581^{*}$ & $0.323^{*}$ & $0.657^{*}$ & $-0.314^{*}$ & $0.395^{*}$ \\
\hline
\end{tabular}

*Spearman's rank correlation, $p<0.01$, 'Spearman's rank correlation, $p<0.05$.

ESS: Epworth Sleepiness Scale, H\&Y stage: Hoehn and Yahr stage, K-PDQ: Korean version-Parkinson's disease questionnaire, LDED: levodopa equivalent dose, MADS: Montgomery-Asberg Depression Scale, MMSE: Mini-Mental Status Examination, NMSS: the non-motor symptoms scale for Parkinson's disease, PD: Parkinson's disease, UPDRS: the Unified Parkinson's Disease Rating Scale.

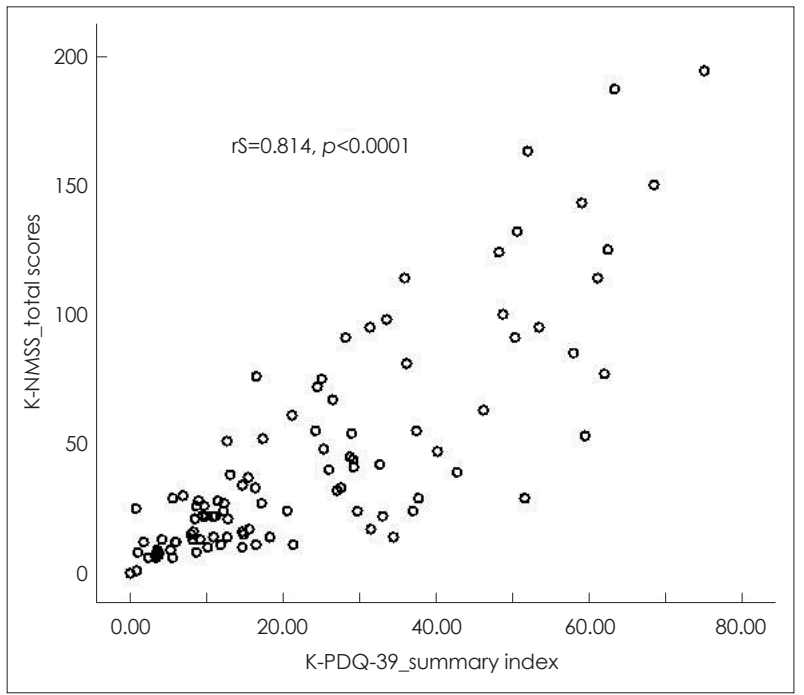

Fig. 1. Correlation analysis of K-NMSS total score and K-PDQ-39. K-NMSS: Korean version-non-motor symptoms scale for Parkinson's disease, K-PDQ: Korean version-Parkinson's disease questionnaire.

for test-retest reliability $(p<0.001)$ (Table 3$)$.

The relationships of the K-PDQ-39 and clinical data with rating scales were analyzed. All clinical variables except age, disease duration, LDED, H\&Y stage, UPDRS parts I, II, and III, mood status (K-MADS), cognition (K-MMSE) and daytime sleepiness (ESS) showed strong correlations with the KPDQ-39 summary index $(p<0.01)$. Age was the only factor that was not significantly correlated with the K-PDQ-39 domains; the other factors-including disease duration, LDED, H\&Y stage, UPDRS parts I, II, and III, K-MADS, K-MMSE and ESS- were significantly correlated with each K-PDQ-39 domain $(p<0.01-0.05)$ (Table 4).

The K-PDQ-39 summary index score demonstrated significant relationships with total NMSS scores $(\mathrm{rS}=0.814, p<0.01$; Fig. 1 and Table 5). Table 5 indicates that most of the K-
PDQ-39 domains were strongly correlated with NMSS items.

\section{Discussion}

There is an increasing need to evaluate HrQoL when managing patients with chronic, degenerative diseases. ${ }^{3,21}$ We translated the most commonly used and validated instrument for evaluating HrQoL in PD patients, the PDQ-39, into Korean, and found the K-PDQ-39 to be a reliable, valid and useful instrument that was easily applicable to the Korean-speaking PD population. The data of the present study were collected from 10 different movement-disorder clinics and interviews were performed by different investigators, which strengthens the positive results of the K-PDQ-39 reliability and validity in terms of suitability for application in clinical practice.

The mean scores in the domains were lower (indicating a lower degree of discomfort) than the results for the original British and other translated, and validated versions, including those in Chinese, Greek, Spanish, American English and Portuguese. ${ }^{7-13,22}$ A possible explanation for this result is that the disease severity according to H\&Y stage being milder and the stages of PD being earlier in the present study than in the patients included in previous studies, since several studies have demonstrated that mean PDQ-39 scores are positively correlated with disease duration as well as disease severity. ${ }^{8,11,12}$ Additionally, disease duration and severity primarily contribute to HrQoL through associated motor complications arising from treatment in late-stage PD. ${ }^{23-25}$ However, the scores were lowest for social support and communication, as also found in the present study. ${ }^{10-12}$ These findings are also reflected in the presence of floor effects in over half of the domains, with no ceiling effects in any of the domains. Social support, communication and stigma domains showed the largest floor effects in this study, which is similar to previous validation studies involving 
Table 5. Spearman's correlation of the K-NMSS and the subscale items of the K-PDQ-39

\begin{tabular}{|c|c|c|c|c|c|c|c|c|c|}
\hline \multicolumn{10}{|c|}{ K-PDQ-39 } \\
\hline NMSS items & Mobility & $\begin{array}{l}\text { Activities of } \\
\text { daily living }\end{array}$ & $\begin{array}{l}\text { Emotional } \\
\text { well-being }\end{array}$ & Stigma & $\begin{array}{l}\text { Social } \\
\text { support }\end{array}$ & Cognition & $\begin{array}{l}\text { Communi- } \\
\text { cation }\end{array}$ & $\begin{array}{c}\text { Bodily } \\
\text { discomfort }\end{array}$ & $\begin{array}{c}\text { PDQ-39 } \\
\text { summary } \\
\text { index }\end{array}$ \\
\hline Cardiovascular & $0.289^{\dagger}$ & $0.260^{\dagger}$ & 0.361 & $0.217^{\dagger}$ & $0.245^{\dagger}$ & $0.303^{+}$ & $0.288^{\dagger}$ & $0.383^{*}$ & $0.394^{*}$ \\
\hline Sleep/fatigue & $0.484^{*}$ & $0.337^{\dagger}$ & $0.476^{*}$ & $0.200^{\dagger}$ & $0.341^{*}$ & $0.427^{*}$ & $0.299^{\dagger}$ & $0.504^{*}$ & $0.614^{*}$ \\
\hline Mood/cognition & $0.538^{*}$ & $0.425^{*}$ & $0.670^{*}$ & $0.421^{*}$ & $0.319^{\dagger}$ & $0.488^{*}$ & $0.433^{*}$ & $0.301^{\dagger}$ & $0.655^{*}$ \\
\hline $\begin{array}{l}\text { Perceptual prob./ } \\
\text { hallucination }\end{array}$ & 0.192 & 0.160 & 0.274 & 0.230 & 0.047 & $0.315^{\dagger}$ & $0.252^{\dagger}$ & 0.165 & $0.302^{\dagger}$ \\
\hline Attention/memory & $0.509^{*}$ & $0.526^{*}$ & $0.348^{*}$ & $0.301^{\dagger}$ & $0.237^{\dagger}$ & $0.699 *$ & $0.460^{*}$ & $0.512^{*}$ & $0.632^{*}$ \\
\hline Gastrointestinal & $0.497^{*}$ & $0.372^{*}$ & $0.339 *$ & $0.300^{\dagger}$ & $0.272^{\dagger}$ & $0.502^{*}$ & $0.401^{*}$ & $0.397^{*}$ & $0.613^{*}$ \\
\hline Urinary & 0.478 & 0.290 & $0.386^{*}$ & 0.133 & 0.161 & $0.379 *$ & $0.201^{\dagger}$ & $0.341^{*}$ & $0.537^{*}$ \\
\hline Sexual function & $0.230^{\dagger}$ & $0.196^{\dagger}$ & 0.101 & $0.075^{\dagger}$ & 0.038 & 0.177 & 0.107 & 0.024 & 0.185 \\
\hline $\begin{array}{l}\text { Miscellaneous_ } \\
\text { pain }\end{array}$ & $0.225^{\dagger}$ & $0.203^{\dagger}$ & $0.255^{\dagger}$ & $0.340^{*}$ & $0.325^{\dagger}$ & $0.209^{\dagger}$ & $0.261^{\dagger}$ & $0.308^{\dagger}$ & $0.305^{\dagger}$ \\
\hline $\begin{array}{l}\text { Miscellaneous_ } \\
\text { taste, smell }\end{array}$ & 0.189 & 0.171 & $0.331^{\dagger}$ & $0.239^{\dagger}$ & 0.087 & $0.348^{*}$ & $0.213^{\dagger}$ & $0.268^{\dagger}$ & 0.420 \\
\hline $\begin{array}{l}\text { Miscellaneous } \\
\text { weight change }\end{array}$ & $0.256^{\dagger}$ & $0.230^{\dagger}$ & 0.154 & $0.224^{\dagger}$ & 0.105 & 0.176 & $0.242^{\dagger}$ & $0.203^{\dagger}$ & $0.242^{\dagger}$ \\
\hline $\begin{array}{l}\text { Miscellaneous_ } \\
\text { excess sweating }\end{array}$ & $0.387^{*}$ & $0.387^{*}$ & $0.281^{\dagger}$ & $0.336^{\dagger}$ & 0.136 & $0.474^{*}$ & $0.272^{+}$ & $0.484^{*}$ & $0.461^{*}$ \\
\hline NMSS_total & $0.632 *$ & $0.515^{*}$ & $0.593^{*}$ & $0.386^{*}$ & $0.305^{\dagger}$ & $0.624 *$ & $0.475^{*}$ & $0.532 *$ & $0.814^{*}$ \\
\hline
\end{tabular}

*Spearman's rank correlation, $p<0.001$, 'Spearman's rank correlation, $p<0.05$

K-NMSS: Korean version-non-motor symptoms scale for Parkinson's disease, K-PDQ-39: Korean version-Parkinson's disease questionnaire.

various languages. ${ }^{8,13,34}$ A cut-off above 0.70 for Cronbach's $\alpha$ coefficient is reportedly considered indicative of acceptable internal consistency and reliability. ${ }^{26}$ The internal consistency of the K-PDQ-39 was satisfactory, since Cronbach's $\alpha$ coefficient ranged from 0.58 to 0.80 . Two of the eight domains failed to reach the standards, and the average correlations of the items comprising the test were very strong (Cronbach's $\alpha$ coefficient $=0.913$ ). Test-retest reliability as calculated by the Guttman Split-Half coefficient value was also adequate, with values ranging from 0.715 to 0.943 . These results suggest that the $\mathrm{K}$ PDQ-39 is a stable and reliable tool.

The relationship between clinical data and K-PDQ-39 was also analyzed. While disease duration, disease severity (H\&Y stage and UPDRS), LDED, depressive mood (K-MADS), cognition (K-MMSE), and daytime sleepiness (ESS) were strongly correlated with K-PDQ-39 domains, age was only strongly correlated with the K-PDQ-39 mobility domain. These results, which are consistent with those of previous studies ${ }^{27,28}$ may be accounted for by several factors. First, patient age has no direct relationship with disease duration or severity, both of which have strong correlations with PD HrQoL. ${ }^{8,11,12}$ Second, the age range of the participants in the present study was limited to4384 years (with a mean of 65.3 years), which Soh et al. ${ }^{21}$ pointed out restricts the ability of HrQoL to discriminate between diverse age groups. Our data also suggest that a longer and more severe case of PD will lower the quality of life. UPDRS (parts I and II) scores were strongly correlated with all items of the K-PDQ-39. The scores for depressive mood and cognition were closely related to nearly all items of the K-PDQ-39, indicating that HrQoL factors are associated with both motor and non-motor symptoms of PD. In particular, the mood status of the patients (as assessed by K-MADS) showed the strongest correlations with all domains of K-PDQ-39 ( $\mathrm{rS}=0.425-0.704$, $p<0.01)$. Similar patterns have been found previously, in that the the presence of depressive symptoms was the main factor associated with a poor quality of life. ${ }^{3,29}$ Concurrently, NMSS items that quantify non-motor symptoms of PD demonstrated strong correlations with K-PDQ-39 scores, which implies that non-motor features of $\mathrm{PD}$ are the most important determinants of quality of life in PD. ${ }^{4,5}$ Although non-motor symptoms are prevalent from the early stages or prestages of motor symptoms of PD, the clinical impact of non-motor aspects on HrQoL has only recently been highlighted. ${ }^{21,30-33}$

The first limitation of the present study was the uneven distribution of disease severity, with most participants having mild disease $(73.5 \%$ of the participants had an $\mathrm{H} \& \mathrm{Y}$ stage of up to 2.0). The late-stage HrQoL of the PD patients therefore might not have been properly evaluated. However, the present study did not aim to assess HrQoL severities in patients, and also showed that the HrQoL had clinical impacts from the relatively early, mild stages of PD. The second limitation of the present study was that other assessments of HrQoL were not com- 
pared with the K-PDQ-39, and hence convergent validity might not have been verified.

In conclusion, we have demonstrated that the K-PDQ-39 is a useful, valid, and reliable instrument for assessing $\mathrm{HrQoL}$ in PD patients. Further detailed investigations of HrQoL in Korean-speaking PD patients should be undertaken using the KPDQ-39.

\section{Conflicts of Interest}

The authors have no financial conflicts of interest.

\section{Acknowledgements}

This work was supported by grants from Sandoz Korea.

\section{REFERENCES}

1. Saunders CD. Parkinson's Disease: A New Hope. Boston, MA: Harvard Health Publications, 2000.

2. Marttila RJ, Rinne UK. Epidemiology of Parkinson's disease in Finland. Acta Neurol Scand 1976;53:81-102.

3. Den Oudsten BL, Van Heck GL, De Vries J. Quality of life and related concepts in Parkinson's disease: a systematic review. Mov Disord 2007; 22:1528-1537.

4. Martinez-Martin P, Rodriguez-Blazquez C, Kurtis MM, Chaudhuri KR; NMSS Validation Group. The impact of non-motor symptoms on health-related quality of life of patients with Parkinson's disease. Mov Disord 2011;26:399-406.

5. Qin Z, Zhang L, Sun F, Fang X, Meng C, Tanner C, et al. Health related quality of life in early Parkinson's disease: impact of motor and non-motor symptoms, results from Chinese levodopa exposed cohort. Parkinsonism Relat Disord 2009;15:767-771.

6. Uitti RJ. Treatment of Parkinson's disease: focus on quality of life issues. Parkinsonism Relat Disord 2012;18 Suppl 1:S34-S36.

7. Jenkinson C, Fitzpatrick R, Peto V, Greenhall R, Hyman N. The Parkinson's Disease Questionnaire (PDQ-39): development and validation of a Parkinson's disease summary index score. Age Ageing 1997;26: 353-357.

8. Peto V, Jenkinson C, Fitzpatrick R, Greenhall R. The development and validation of a short measure of functioning and well being for individuals with Parkinson's disease. Qual Life Res 1995;4:241-248.

9. Bushnell DM, Martin ML. Quality of life and Parkinson's disease: translation and validation of the US Parkinson's Disease Questionnaire (PDQ-39). Qual Life Res 1999;8:345-350.

10. Martínez-Martín P, Frades Payo B. Quality of life in Parkinson's disease: validation study of the PDQ-39 Spanish version. The Grupo Centro for Study of Movement Disorders. J Neurol 1998;245 Suppl 1:S34-S38.

11. Tsang KL, Chi I, Ho SL, Lou VW, Lee TM, Chu LW. Translation and validation of the standard Chinese version of PDQ-39: a quality-of-life measure for patients with Parkinson's disease. Mov Disord 2002;17: 1036-1040.

12. Katsarou Z, Bostantjopoulou S, Peto V, Alevriadou A, Kiosseoglou G. Quality of life in Parkinson's disease: Greek translation and validation of the Parkinson's disease questionnaire (PDQ-39). Qual Life Res 2001;10:159-163.

13. Luo W, Gui XH, Wang B, Zhang WY, Ouyang ZY, Guo Y, et al. Validity and reliability testing of the Chinese (mainland) version of the 39item Parkinson's Disease Questionnaire (PDQ-39). J Zhejiang Univ Sci B 2010;11:531-538.

14. Hughes AJ, Daniel SE, Lees AJ. The clinical features of Parkinson's disease in 100 histologically proven cases. Adv Neurol 1993;60:595-
599.

15. Langston JW, Widner H, Goetz CG, Brooks D, Fahn S, Freeman T, et al. Core assessment program for intracerebral transplantations (CAPIT). Mov Disord 1992;7:2-13.

16. Hoehn MM, Yahr MD. Parkinsonism: onset, progression and mortality. Neurology 1967;17:427-442.

17. Movement Disorder Society Task Force on Rating Scales for Parkinson's Disease. The Unified Parkinson's Disease Rating Scale (UPDRS): status and recommendations. Mov Disord 2003;18:738-750.

18. Kang Y, Na DL, Hahn S. A validity study on the Korean Mini-Mental State Examination (K-MMSE) in dementia patients. J Korean Neurol Assoc 1997;15:300-308.

19. Johns MW. A new method for measuring daytime sleepiness: the Epworth sleepiness scale. Sleep 1991;14:540-545.

20. Chaudhuri KR, Martinez-Martin P, Brown RG, Sethi K, Stocchi F, Odin P, et al. The metric properties of a novel non-motor symptoms scale for Parkinson's disease: Results from an international pilot study. Mov Disord 2007;22:1901-1911.

21. Soh SE, Morris ME, McGinley JL. Determinants of health-related quality of life in Parkinson's disease: a systematic review. Parkinsonism Relat Disord 2011;17:1-9.

22. Carod-Artal FJ, Martinez-Martin P, Vargas AP. Independent validation of SCOPA-psychosocial and metric properties of the PDQ-39 Brazilian version. Mov Disord 2007;22:91-98.

23. Chapuis S, Ouchchane L, Metz O, Gerbaud L, Durif F. Impact of the motor complications of Parkinson's disease on the quality of life. Mov Disord 2005;20:224-230.

24. Chrischilles EA, Rubenstein LM, Voelker MD, Wallace RB, Rodnitzky RL. Linking clinical variables to health-related quality of life in Parkinson's disease. Parkinsonism Relat Disord 2002;8:199-209.

25. Gómez-Esteban JC, Zarranz JJ, Lezcano E, Tijero B, Luna A, Velasco $\mathrm{F}$, et al. Influence of motor symptoms upon the quality of life of patients with Parkinson's disease. Eur Neurol 2007;57:161-165.

26. Cronbach LJ. Coefficient alpha and the internal structure of tests. Psychometrika 1951;16:297-334.

27. Schrag A, Jahanshahi M, Quinn N. What contributes to quality of life in patients with Parkinson's disease? J Neurol Neurosurg Psychiatry 2000;69:308-312.

28. Schrag A, Selai C, Mathias C, Low P, Hobart J, Brady N, et al. Measuring health-related quality of life in MSA: the MSA-QoL. Mov Disord 2007;22:2332-2338.

29. Schrag A. Quality of life and depression in Parkinson's disease. J Neurol Sci 2006;248:151-157.

30. Muslimovic D, Post B, Speelman JD, Schmand B, de Haan RJ; CARPA Study Group. Determinants of disability and quality of life in mild to moderate Parkinson disease. Neurology 2008;70:2241-2247.

31. Qin Z, Zhang L, Sun F, Liu H, Fang X, Chan P, et al. Depressive symptoms impacting on health-related quality of life in early Parkinson's disease: results from Chinese L-dopa exposed cohort. Clin Neurol Neurosurg 2009;111:733-737.

32. Rahman S, Griffin HJ, Quinn NP, Jahanshahi M. Quality of life in Parkinson's disease: the relative importance of the symptoms. Mov Disord 2008;23:1428-1434.

33. Winter Y, von Campenhausen S, Gasser J, Seppi K, Reese JP, Pfeiffer $\mathrm{KP}$, et al. Social and clinical determinants of quality of life in Parkinson's disease in Austria: a cohort study. J Neurol 2010;257:638-645.

34. Hagell P, Whalley D, McKenna SP, Lindvall O. Health status measurement in Parkinson's disease: validity of the PDQ-39 and Nottingham Health Profile. Mov Disord 2003;18:773-783.

35. McHorney CA, Ware JE Jr, Lu JF, Sherbourne CD. The MOS 36-item Short-Form Health Survey (SF-36): III. Tests of data quality, scaling assumptions, and reliability across diverse patient groups. Med Care 1994;32:40-66. 